\title{
Working on Learning: How the Institutional Rules of Environmental Governance Matter
}

Journal of Environmental Planning and Management, pre-publication draft May 2019

Tanya Heikkila, University of Colorado-Denver

Andrea K. Gerlak, University of Arizona

Abstract: Learning among actors engaged in environmental governance can be a critical pathway toward institutional change. Learning, however, is often unintentional or idiosyncratic in environmental governance. This paper considers how the rules structuring an environmental governance process can enable or constrain the institutional work of learning. We draw insights from theories of learning and from the Institutional Analysis and Development (IAD) Framework's rule typology to identify how particular types of rules matter in learning. We examine how these insights can help uncover lessons from five empirical studies of learning in the environmental governance literature. We conclude with a discussion of the implications of our analysis for devising rules of environmental governance to intentionally foster learning.

\section{Introduction}

Learning is an important feature of institutional work in environmental governance. Within a governance context, learning in general involves both "processes" (e.g., actors acquiring, disseminating, and translating information or ideas) and "products", such as changes in the beliefs or behaviors among governance actors (Heikkila and Gerlak, 2013). Multiple processes or pathways for learning are recognized in the environmental governance literature. For example, learning can occur in on-going shared efforts of diverse groups of decision makers to engage in problem solving around complex issues, such as in co-management processes (e.g., Newig et al., 2016; Blackmore et al., 2016; Armitage et al., 2008; Huitema et al., 2009). Through such processes, environmental governance scholars recognize that learning can lead to beneficial products, such as increasing adaptive capacity of resource governance regimes (Pahl-Wostl, 2009; Vinke-de Kruijf and Pahl-Wostl, 2016), or creating "shared conceptions of problems and solutions in organizational fields" (Zietsma and McKnight, 2009: 145). Scholars of institutional work also see learning as a way to adapt to emergent problems (Kraatz, 2009: 79) or to address growing complexities in the external environment (Bergsma et al., 2017).

Despite the importance of learning for the institutional work of environmental governance, learning is often unintentional and idiosyncratic. However, lessons from research on environmental governance that explores factors that facilitate learning can be helpful in thinking about the institutional work that may be needed to make learning more intentional (Gerlak et al., 2017). For example, literature on social learning has argued that environmental governance processes can be designed to allow actors to develop shared meanings and more robust institutional choices (e.g., Short and Duana, 2016; Noguera-Mendez et al., 2016; Salvini et al., 2016). Additionally, scholars have looked at how transformative learning -- or fundamental changes in values and assumptions -- can lead to more sustainable solutions to complex environmental governance problems, such as biodiversity loss or climate change (Sims and Sinclair, 2008; Tschakert and Dietrich, 2010; Diduck et al., 2012; O'Brien, 2012; Rogers et al., 
2013). By highlighting how to design governance processes intentionally for learning, this literature offers important parallels with the concept of 'institutional work' (Beunen and Patterson, 2016).

The opportunities and mechanisms for learning in environmental governance can be influenced by the institutions, or rules, that structure a governance process. These rules include who is allowed to engage in governance, what type of information is permitted or required in a decision context, the scope of the problem that a governance process can address, and the costs and benefits that are assigned to particular types of institutional outcomes (Ostrom, 2005). In the environmental governance context, these rules can be complex when designed to tackle crossscale environmental problems (Pahl Wostl et al., 2007). Thus, governance actors need to understand how to diagnose, design, and modify rules in ways that can foster learning and ultimately institutional change and adaptation.

Using insights on a typology of rules developed within the Institutional Analysis and Development (IAD) Framework (Ostrom, 2005) and lessons from across the environmental governance literature on learning, this paper explores how the design of rules of a governance process condition opportunities for learning. We then use the rule typology to help compare and contrast five empirical studies of learning in the environmental governance literature. Following the case analysis, we then discuss the implications for devising rules of environmental governance that foster learning. These theoretical insights can then help heighten our understanding of the interplay between actors and institutional settings, which is at the heart of institutional work.

\section{Challenges to Learning in Environmental Governance}

Recent articles tackle learning in environmental governance from a variety of conceptual approaches, from multi-actor learning (Schmid et al., 2016) and co-learning (Tschakert et al., 2016) to governance learning (Newig et al., 2016), policy learning (McFaden and Huitema, 2016) and social learning (e.g., Short and Duana, 2016; Noguera-Mendez et al. 2016; Salvini et al., 2016). However, learning does not guarantee improved governance outcomes. People can learn from inaccurate information and inappropriate behaviors. Some scholars argue that more reflective and deeper levels of learning may be necessary to fundamentally change our institutions and environmental practices (Diduck et al., 2012; Rogers et al., 2013).

Deeper levels of learning further require some intentionality. In this sense, deep learning may demand learning processes (i.e., often starting with reflection of assumptions or beliefs), and a willingness to instill learning products (i.e. changes in those assumptions or beliefs) into behaviors, routines, or strategies (see Gerlak and Heikkila, 2011). Also, while this conceptualization of learning is grounded in individual learning, it can apply to collective contexts, such as when stakeholders "are brought together to engage in an iterative, facilitated process of critical reflection and inquiry aimed at provoking transformational changes in cognition and practice" (Diduck et al., 2012: 1313). Heikkila and Gerlak (2013) further recognize that the interplay between individual learning and collective learning is critical for understanding learning in a governance context. 
Various scholars have highlighted the value of devising collective decision-making or governance processes to promote learning. For example, the literature on "double-loop" learning emphasizes the importance of changing fundamental assumptions and world views, rather than simply changing behaviors, as a more sustainable pathway toward improving organizational outcomes (Argyris and Schon, 1996). Triple loop learning highlights the need to change processes to foster double-loop learning - or engaging in learning how to learn (Ison and Watson, 2007). Similarly, social learning focuses on the importance of governance actors establishing new capacities to understand the perspectives of other actors, as well as the interactions between social-ecological systems (Folke et al., 2005; Pahl-Wostl. et al., 2007; Karpouzoglou et al., 2016). In other words, these approaches take learning beyond the idea of changing behaviors, to promote processes that can help change fundamental assumptions and understandings. Some researchers argue that such learning is essential for tackling major environmental changes across complex systems, or producing transformative learning (Sims and Sinclair, 2008; Siebenhuner et al., 2016).

Many factors, however, may impede learning in a governance context. As a result, even where governance processes are well-designed, learning can be challenging. Mezirow (2003), for example, argues that it is particularly challenging for individuals to even recognize their assumptions, political biases, or world views because they are taken for granted. Additionally, individuals may be resistant to learning about ideas that do not comport with their own ways of establishing meaning (Mezirow, 1994), and they often interpret information to assimilate it into preexisting attitudes, assumptions and beliefs (Lord and Taylor, 2009). Since individuals are limited in their cognitive abilities to process information, the information they attend to at any given time is likely to be limited or selectively filtered (Simon, 1945; Jones and Baumgartner, 2005). Such individual level cognitive constraints can impede learning in collective governance settings (Heikkila and Gerlak, 2013). For example, when individual "ways of knowing" (Lejano and Ingram, 2009; Mukhtarov and Gerlak, 2014) differ widely within a group, the ability to translate and share new ideas collectively is constrained (Gerlak and Heikkila, 2013). In addition to individual characteristics, the structure of a group or a network, according to social psychologists, can shape the accuracy of collective memory (Spinney, 2017). For instance, information that is not collectively discussed is less likely to be encoded into the memories of members of a group, or where distinct subgroups are not connected through network ties between participants, memories among subgroups are less likely to align (Spinney, 2017).

Overcoming such barriers is not simple. In our previous research, we recognized that the structure of governance processes, social interactions, functional domain of processes, as well as other contextual factors, can influence the degree to which learning occurs (Heikkila and Gerlak, 2013). Underlying these factors that shape learning are the basic institutional rules of a governance process. As recognized in Heikkila and Gerlak's collective learning framework (2013), such rules can constrain or enable particular types of social interactions, information acquisition, and set the scope of the functional domain. However, limited attention has been paid to examining how different types of rules matter for learning in a governance context.

Below we use the IAD framework's rule typology and insights from literature on learning in environmental governance to draw the connection between institutional rules and learning. Other scholars have recognized the value of the IAD for informing research on learning. For example, 
Huntjens et al. (2012) used the design principles of successful common pool resource governance that IAD scholars have identified factors that are likely to support policy learning around climate change adaptation. More recently, McFagden and Huitema (2016) employed the IAD rule typology to classify three ideal types of environmental governance experiments (technocratic, advocacy, and boundary), which they hypothesize are associated with different levels and categories of learning. Dell'Angelo and colleagues (2016) also have explored how the Ostrom design principles of successful common pool resource governance relate to learning in in adaptive community water governance in rural Kenya. Finally, a the IAD has further evolved in the, the Social Ecological Systems (SES) Framework (McCord et al., 2017), which recognizes the importance of identifying types of rules that affect outcomes of environmental governance, such as learning (Ostrom, 2011). Our analysis differs from previous IAD and SES studies by specifying how the design of particular types of rules may matter for fostering learning by drawing lessons from learning theories about the rule typology.

\section{How the Design of Rules Can Structure Learning}

Institutions, including rules, norms, and shared strategies, structure the actions and interactions of collective actors (Ostrom, 2005). Arguably then, institutions may create opportunities for people to learn together in governance settings, or they may create constraints on learning. Here we are interested in how rules, as part of institutional design, can be used to promote learning. When diagnosing rules, it is important to understand the "rules-in-use" - or what is practiced by a collective group (Ostrom, 2005), which can differ from the rules written into formal governance documents.

To diagnose rules in any collective "action situation" (i.e., a governance process), Ostrom (2005) developed a rule typology, which differentiates among boundary, position, choice, information, aggregation, payoff and scope rules. Research using the rule typology has not directly examined the relationship between different types of rules and learning. However, Ostrom (2007: 30-31) has recognized that the diverse "institutional repertoire" or set of rules that individuals have available "affects their capacity to change their institutions to improve learning and other outcomes". To help explore then how rules might matter with respect to learning, we consider the various rule types, and develop some general theoretical insights into how the design of these types of rules might relate to learning based on theoretical guidance from the learning literature. Our goal is not to identify which type of rule matters the most or to assess these rule types normatively. Rather, the goal is to help situate some of the theoretical insights on governance processes and learning within the language of rules. In turn, this can help inform the ways in which institutional work can support learning. Of course, it is how the rules are designed that matters. Additionally, while we introduce these rule types individually, we recognize that they interact or are configural. As a result, the combination of particular rule types structuring a governance setting may be more important in shaping learning than any one rule type on its own.

Boundary rules and position rules outline the contours of participation in an institutional setting. Boundary rules define who is allowed to participate in a governance process, and how they are allowed to enter or exit that process (Ostrom, 2005). Position rules establish the specific roles that the actors in a process are assigned to and the number of different positions. The design of both boundary and position rules can is likely to be important for learning in several ways. First, 
we know from the learning literature that governance processes the include diverse stakeholders (via boundary rules) with distinct interests, backgrounds, experiences, and knowledge can facilitate learning (Axelsson et al., 2013). Similarly, widespread differentiation in the responsibilities of actors (via position rules) can promote more extensive access to new and diverse sources of information and knowledge (Pedler et al., 1991; Liebskind et al., 1996; Olsson et al., 2004; Bodin et al., 2006), and ultimately foster learning (Keen and Mahanty, 2006; Weber, 2009). In other words, more open boundary rules and diverse position rules may allow information to be acquired from more diverse perspectives, which may help spur transformative ideas. This expectation is supported by the literature on environmental governance networks, which suggests that more homogeneous networks create constraints on learning (Henry and Vollan, 2014), while more heterogeneous or inter-sectoral networks may allow for the type of "bridging" ties that are needed for knowledge acquisition (Dow et al., 2013). At the same time, for learning to move from individuals to a collective it may be important to include position rules for a boundary spanner or broker in heterogeneous groups (Hoe, 2006; Ramiro and Brad, 2008).

Information rules structure who is required to collect information, what type of information must or may be gathered, and who receives information (Ostrom, 2005). Information rules therefore may determine the extent to which data or evidence on the resource being governed, and the actions of actors taken in the past, will be available for learning. As with boundary and position rules, the literature on learning in environmental governance provides direct insight on the design features of information rules that may be supportive of learning. For example, to promote learning, information rules should allow for not only ongoing knowledge building, but also the ability to detect and explore surprises or unexpected information (Fazey et al., 2005; Henry, 2009). Information rules can also create opportunities for learning if they require diverse forms of knowledge be incorporated into dialogue and discussion in a group (Dyck et al., 2005; Weber, 2009). Learning about issues or processes among and within a group may occur when participants must establish new "ways of knowing" that are defined by the group, and not by any individual participant (Lejano and Ingram, 2009). Information rules can also be important for helping build trust among actors if they ensure regularized reporting (i.e. people learn to trust others if they follow through with information), and trust building can be critical for organizational learning (Lipshitz et al., 2002). Information rules that encourage dissemination of new ideas broadly across a group (e.g. requirements for regular meetings, performance reviews) and allow for dialogue and transparency about this information can also help create opportunities to embed learning in a group (Nonaka, 1994). Of course, greater access to information may not necessarily result in increased knowledge or learning.

Choice rules determine the actions that participant may or must undertake (or not) in a decision process, and the conditions under which these actions might be required or allowed (Ostrom, 2005; Ostrom and Basurto, 2011). In general, we would expect that choice rules that give more flexibility to actors to experiment in their actions within a group can help facilitate learning. At the same time, choice rules that may require intentional and periodic revisiting of fundamental guiding assumptions of the institutions - or the rules themselves - might also be helpful in learning (Walters and Holling, 1990). Finally, choice rules can require collective routines, which the learning literature sees as helpful for embedding newly learned ideas across a group (Feldman, 2000; Zollo and Winter, 2002). 
Aggregation rules structure who, or what subset of a collective group, can make decisions about the allowable actions of that group (Ostrom, 2005). We can think of aggregation rules as similar to voting rules. They may determine whether a single actor or of multiple actors have authority to change decisions, or what weight is given to the voice of particular actors over others. While we do not have specific expectations from the literature about how the design of aggregation rules matter for learning, aggregation rules that allow more equal weight of a larger proportion of actors involved in a governance context might facilitate deeper reflection of ideas that are known to support learning. Still, there is no guarantee that the collective decisions of actors will reflect learning of individuals (Etheredge and Short, 1983; Heikkila and Gerlak, 2013).

Payoff rules affect the benefits and costs assigned to actors in light of the outcomes achieved and the actions chosen by the actors (Ostrom, 2005). The design of these rules are important for learning for a couple reasons. First, they can define the costs of failed experiments. Rules that dis-incentivize actors to try new things by making the costs of failure high (e.g. dismantling a governance program if it does not produce immediate results) can be problematic or constrain learning. At the same time, rules that encourage self-assessments can promote the type of reflection that is necessary for learning (Walters and Holling, 1990). This can also reward leadership characteristics in a governance setting that embraces new ideas, experimentation and risk-taking, which learning scholars recognize as critical for learning (Argyris and Schön, 1978; Schein, 1993; Lipshitz et al., 2002).

Finally, the IAD identifies scope rules as establishing what outcomes are allowed within a governance context. Our previous work has argued that collective processes that have a welldefined functional domain (e.g. perhaps more constrained scope rules) might make it easier for deeper reflection on specific issues, which can foster learning (Gerlak and Heikkila, 2011). That said, a narrowly-defined scope could hinder understanding or capacity to manage complex environmental problems Thus, having scope rules that are broad enough to allow for flexibility and adaptation to incoming information may be critical. This also raises the potential importance of having governance processes that are nested, allowing for focused scope rules at smaller scales, and then linking those processes to larger-level decision-making (Huitema et al., 2009; Van Kerkhoff and Szlezák, 2010; Jordan et al., 2015; Cole, 2015). This may allow for critical feedback loops of information to emerge over time, which then supports learning (Berkes, 2009; Diduck, 2010; Hagemeier-Klose et al., 2014).

\section{Illustrating the Value of Rules from Cases of Learning}

We examine five empirical examples to illustrate in practical terms how the designs of different rule types might matter in understanding the role of institutions in learning. Similar to the broader scholarship on learning in environmental governance, our five case examples reflect different types of learning (e.g., social learning, adaptive, transformative) and a diverse set of scales, from more community level learning to learning at a regional level and then learning in international intergovernmental organizations. Finally, they reflect a variety of environmental issues, such as wildlife and land planning to water and flooding issues to Arctic management. While three of the cases (Armitage, Seibenhuner and Pahl-Wostl) mention "rules", they do so more in the general context of institutions. The cases themselves do not adopt the language of the 
rule typology, but rather provide a way to illustrate in practical terms how these rule types might matter in our understanding of learning and institutions for environmental governance.

We systematically examine each case, looking for how the authors describe the design of the governance processes and use that information to draw inferences about the types of rules present in the cases. Each case also describes learning processes and/or outcomes, which allows us to consider how the rule types might be associated with learning. We begin with a very brief background on the context and extent of the case (especially how they engage with and define learning) recognizing that we are primarily focused on looking for the presence or absence of linkages to the rule types. We examine the implications of the expected relationships between rules and learning using lessons from the learning literature, as outlined earlier. The goal is not to test empirically the ways in which rules matter but rather to lay out a theoretically grounded approach for examining how the design of different types of rules matter. Doing so, we argue, provides a foundation for a more rigorous approach to comparative analysis of learning in environmental governance, which may then inform the development of institutional design principles for intentional learning. We recognize that other factors, such as the biophysical context or community conditions, can affect learning. However, analyses of the full suite of conditions that affect learning are outside the scope of this paper.

\section{Illustrative case example \#1: Learning in community wildlife planning in the U.S.}

In a study of community wildlife protection planning in the eastern U.S., Brummel et al. (2010) study learning processes and outcomes at the local level for wildlife planning, with a focus on how the design of the collaborative process matters. In comparing learning outcomes across three cases, they found learning was often constrained; most learning involved transforming institutional and organizational views of wildfire planning as opposed to incorporating new substantive management practices.

Brummel and colleagues' (2010) research highlights how the type of actors participating influenced the learning outcomes. Their research suggests that when boundary rules limit participation to particular individuals (in this case, state and local foresters and fire chiefs), a specific type of institutionalized knowledge of wildfires was present, which constrained learning with the group. Because the groups of actors consisted largely of traditional agency partners, they focused on existing management goals of fire suppression and fuels mitigation. As a result, they were less innovative in designing new practices and instead the process produced more organizational coordination around fire management. This also reflects more constrained information rules in practice. Additionally, the authors indicate that although the actions of the groups (or choice rules) were open to a variety of possible actions, they interpreted their potential actions narrowly, which the authors suggest hindered transformational learning. This highlights the importance of how rules are interpreted or used in practice.

Despite the constraints on learning in these cases, Brummel and colleagues identified some learning successes that we can link to rules. For example, they found improved learning outcomes around basic information about fire behavior and management were associated with non-agency community participants, who had limited previous knowledge of wildfires. In other words, more open boundary rules were important for learning new information. Deeper forms of 
learning also occurred where there was extended engagement, or a longer time-frame established by groups, which we attribute to scope rules that provide a flexible time horizon for governance activities.

\section{Illustrative case example \#2: Learning in international environmental organizations}

Siebenhuner (2008) studied organizational learning in eight international organizations with a focus on international environmental policy over more than a 10-year period, looking for evidence of reflexive and adaptive learning, and the conditions supporting learning. This research found that reflexive learning induced fundamental changes in organizational structures and their practices. Adaptive learning, on the other hand, merely brought the organization in line with the demands of external stakeholders and induced only minor changes inside the organization. While external factors, like national governments and NGOs were influential in promoting adaptive learning, Siebenhuner (2008) argues that reflexive learning processes demand organizations with some leeway to learn and change direction, and to have enough formal or informal autonomy from external actors to acquire and pursue knowledge independently.

Siebenhuner (2008) focused on the role of learning mechanisms, such as the creation of task forces, independent evaluation reports, staff retreats, expert workshops, and project reviews. These mechanisms were used to acquire new knowledge and to identify and implement solutions to organizational problems. He found that the deepest forms of learning - reflexive learning -required a combination of independent and external knowledge with internal knowledge to allow for new ideas in to the debate. We attribute this to information rules that require scanning both the internal and external environment in activities such as retreats and workshops. This research also suggested that reflexive learning was a result of deliberate and systematic reflection on past experiences and the fundamental re-thinking of their strategies and objectives towards environmental issues. This suggests that choice rules that are flexible and open to alternative courses of action, depending on the evidence from information rules, can support learning.

In addition, this research highlighted how organizations that are multi-issue in nature with broad scope rules had more leeway to engage in reflexive learning. In contrast, single-issue organizations with a narrow mandate were restricted to adaptive learning. The scope rules of the organizations also influenced the form of learning by delineating the areas of activity that can be supported by the choice rules, and organizational decision-making structures set by position rules. In a few organizations, this research found that individual agents of change played a significant role in the emergence of reflexive and adaptive learning processes. These change agents held leadership positions, reflecting position rules; there was no case of an effective learning process triggered by officers from medium or lower levels of the organizational hierarchy.

\section{Illustrative case example \#3: Learning in stakeholder water management in Europe}

Muro and Jeffrey (2012) conducted a survey of stakeholder groups for water management, comparing learning in German working groups to Irish advisory councils. The stakeholder groups differed in their design, especially in how stakeholder interactions were organized, 
including the time frame, group size, and mode of communication, which illustrate scope, boundary, and information rules, respectively. Based on their comparative analysis, they found that overall advisory councils provided fewer opportunities for extended engagement, information exchange, and interaction than the working groups.

Muro and Jeffery (2012) were interested in understanding what process factors were associated with relational changes (such as trust and relationships) versus cognitive changes (generation of new knowledge and the transformation of views). For them, relational changes result in the development of new relationships and a strengthening of existing relationships, often involving a transformation in the way individuals perceive others and place themselves within the group. This suggests that choice rules for governance processes cannot focus merely on the "functional" domain of the organization. Choice rules that require social engagement may also be important. Additionally, the case highlights the role of information rules that require open and transparent sharing of knowledge. Participants in both groups reported strong cognitive change, by increasing their knowledge about water and river basin management, as well as their understanding of the interests of other stakeholders.

But evidence that stakeholders integrated this information into their own perspective, assumed to be crucial for the development of a shared understanding of the environmental situation at hand, was rarer in both studied groups. The transformation of views and the development of a shared group identity were harder to achieve. Relational change occurred where there was more time for the engagement process and the overall arrangement allowed group members to actively engage with one another and the subject matter. Again, this suggests more flexible choice rules that require social dialogue may be important. At the same time, it can speak to the need for aggregation rules that require consensus building before decisions are made.

\section{Illustrative case example \#4: Learning in the Canadian Arctic}

Armitage et al. (2011) studied three co-management cases from the Canadian Arctic to understand the institutional mechanisms through which co-management actors can learn to learn, or learn to be adaptive. They found evidence of single loop or instrumental learning to improve management decisions, as well as double or triple loop learning in which participants in the cases revised their assumptions, worldviews, and governance practices. Double loop learning was evidenced by an alteration in how management practices were understood and managed, and a reframing of declining species. The role of knowledge in ongoing learning-by-doing characterized two of the three co-management cases revealing fundamental shifts in practice. Ecological and management crises in these cases helped catalyze new approaches and openness to competing knowledge claims. This suggests that open information rules, but also payoff rules that enable experimentation, may have been necessary for intentional learning.

In all three cases, Armitage et al. (2011) found that the promotion of multi-layered institutional arrangements, including roles of bridging organizations that link local actors with government officials and serve as clearing houses for information and conflict, helped promote learning. This highlights that nested institutional designs can help facilitate opportunities for open access to information, but also extend the boundary of actors who can play a role. Their findings point to the importance of a long-term commitment to institution building via polycentric and long-term 
scope rules. They also highlight how choice rules and information rules sustain difficult social processes, where particular individuals or groups may not feel as though their views are heard or sufficiently integrated into the knowledge co-production processes. Although indigenous actors were included in the knowledge co-production processes, as set out by the boundary rules, a lack of integration of indigenous knowledge through aggregation rules served as barriers or obstacles to learning. This suggests the importance of choice rules that facilitate diverse modes of communication and social interaction.

\section{Illustrative case example \#5: Learning in European flooding policy}

In comparative case research of case studies of flooding in Europe, Pahl-Wostl et al. (2013) highlight the importance of informal settings for generating new knowledge and innovative policy approaches needed for institutional change. Overall, their findings acknowledge the difficulty of intentionally managing or steering institutional change, and how major structural transformations are necessary to facilitate and sustain a paradigm shift toward integrated flood management.

In the case of flooding in Hungary, a shadow network, which acted informally and outside the institutional setting, was effective in integrating different kinds of knowledge and bridging levels from local to regional to national. It created a broad boundary rule-in-use. . Yet, their performance was dependent upon contextual factors, such as flooding catastrophes or influential individuals, rather than more formally established relationships. In the absence of a strong formal government institutional setting, the network served to engage stakeholders from lower levels in policy development thereby, expanding the boundary rules. While the shadow network effectively used windows of opportunity to influence the formal policy process, it failed root new insights permanently into established policy networks in Hungary.

Similarly, in the absence of formal learning processes in the case of the Rhine River in the Netherlands, informal learning resulted from opposition to policy plans by diverse groups united for a limited time by their opposition to governmental plans. The opposition resulted in innovation in the overall implementation of flood protection measures by integrating environmental considerations. The changes in implementation mobilized a learning process at the national level characterized by information rules and broad position rules that allowed for participation by a diverse and heterogeneous group of governmental and nongovernmental actors. Despite the high visibility of the new approach, integrated knowledge and ecological considerations were not formally included in an integrated governmental policy until flooding occurred in the 1990s. The dominant technocratic mode of flood management, which suggests more limited choice rules, served to suppress formal public involvement - in effect, creating narrow de facto boundary rules. Vertical integration was necessary to involve actors from the implementation level in policy development and to support feedback experiences from implementation to strategic goal setting and policy formulation.

In all three cases examined by Pahl-Wostl et al. (2013), leadership of individuals, as defined by the position rules, was important for the development of new ideas. The authors caution, however, about linkages between learning and policy processes that hinge on individual actors. These linkages are fragile if the innovative approaches are not codified in formal institutions - or 
made clear by choice and payoff rules. The cases further suggest that in the case of flooding policy, it might be easier to integrate environmental considerations into the heavily technocratic and expert-driven management approach, through a change in information rules, as opposed to integrating and expanding participation through boundary and position rules.

\section{Discussion}

Based on the selected empirical cases of learning described above, we see general trends that support our expectations about the importance of how the design of different types of rules matters for learning. In Table 1 below, we synthesize the lessons from the five case studies examined here. The findings suggest ways in which evidence from cases that exhibited both the presence and absence of different features of rule design shape learning. We do not place weight based on the frequencies associated with these findings because we are relying on a purposive and not a representative sample of cases. As such, the table should not be read as fixed propositions about learning and rule types. Rather they illustrate a set of initial expectations on rule design features that could be examined across a larger set of cases that can also take into account how these rule design features interact with and are shaped by other factors, such as biophysical conditions and actor characteristics.

Table 1. IAD Rules and case study findings

\begin{tabular}{|c|c|c|}
\hline Rule type & Definition & Findings \\
\hline Boundary & $\begin{array}{l}\text { Identify the prerequisites of } \\
\text { individuals eligible to occupy a } \\
\text { position }\end{array}$ & 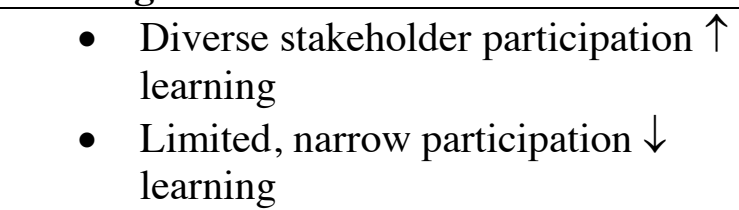 \\
\hline Position & $\begin{array}{l}\text { Identify roles to be filled and the } \\
\text { number of individuals that can } \\
\text { occupy a given position }\end{array}$ & $\begin{array}{l}\text { - Leaders promoting learning } \\
\text { processes } \uparrow \text { learning }\end{array}$ \\
\hline Scope & $\begin{array}{l}\text { Identify required, specified or } \\
\text { prohibited outcomes. May } \\
\text { identify the parameters of } \\
\text { outcomes variables to be affected }\end{array}$ & $\begin{array}{l}\text { - } \\
\text { - } \\
\text { Ability to respond to new } \\
\text { information } \uparrow \text { learning }\end{array}$ \\
\hline Information & $\begin{array}{l}\text { Identify what is permitted, } \\
\text { obliged or prohibited channels of } \\
\text { communication, how information } \\
\text { is to be transmitted, to whom, } \\
\text { when, and in what form }\end{array}$ & $\begin{array}{l}\text { - Internal and external knowledge } \\
\text { brought to bear } \uparrow \text { learning } \\
\text { - } \begin{array}{l}\text { Diverse forms of knowledge } \uparrow \\
\text { learning }\end{array}\end{array}$ \\
\hline Choice & $\begin{array}{l}\text { Specify specific actions - what an } \\
\text { actor must, must not, or may do }\end{array}$ & $\begin{array}{l}\text { - Flexible rules open to } \\
\text { experimentation and requiring } \\
\text { particular information types } \uparrow \\
\text { learning } \\
\text { - Narrow interpretation of choice } \\
\text { rules } \downarrow \text { learning }\end{array}$ \\
\hline Aggregation & Determine who can make & - Exclusion of particular groups $\downarrow$ \\
\hline
\end{tabular}




\begin{tabular}{|c|c|c|}
\hline & decisions & learning \\
\hline Payoff & $\begin{array}{l}\text { Assign extrinsic rewards or } \\
\text { sanctions to specific actors } \\
\text { relative to specified actions }\end{array}$ & $\begin{array}{l}\text { - Rewarding experimentation and not } \\
\text { punishing failed experiments } \uparrow \\
\text { learning }\end{array}$ \\
\hline
\end{tabular}

Overall, more open boundary, information, scope, and choice rules stand out as particularly relevant in the cases. This supports our previous work that recognizes the need for diversity in collective membership and opportunities to promote sharing of diverse forms of information and ideas in a governance process (Gerlak and Heikkila, 2011). Open boundary rules can facilitate diverse stakeholder participation, which can promote learning processes and outcomes. The types of information rules that we identified from the cases indicate the importance of requiring diverse forms of both internal and external knowledge. Open scope rules can serve to extend engagement that may be necessary for learning, or allow for new information and participant engagement and response. Scope rules can highlight cross-scale interactions, which much of the literature views as crucial and necessary opportunities for learning (Clark and Clarke, 2011; Folke et al., 2002, 2010; Pahl-Wostl, 2009; Vinke-de Kruijf and Pahl-Wostl, 2016).

Choice rules may help open pathway for experimentation, or for opportunities for dialogue and social engagement, which can heighten learning. Conversely, a narrow interpretation of choice rules dictating what actors must or must not do, can hinder learning. The learning literature in environmental governance has a long history around experimentation. Adaptive governance and management scholarship emphasizes trial by error practices (Gunderson et al., 1995; Gunderson and Holling, 2002; Folke et al., 2005). If given the freedom dictated by the choice rules, leaders may play important roles in fostering new ideas, openness to information sharing, as well as a willingness to experiment, take risks, and make mistakes (Argyris \& Schön, 1978; Schein, 1993; Driver, 2002; Lipshitz et al., 2002).

Yet, some research also suggests limits to experimentation in learning. In a recent study of learning among German policymakers engaged in implementing the European Floods Directive, Newig et al. (2016: 359) found that decision-makers overwhelmingly had negative connotations about the risks associated with experimentation, limiting their perception of any potential advantages or benefits. Similarly, in our earlier research, we found that although experimentation may be a potential component of the process that leads to learning products, it is viewed as a less commonly used learning process than other forms of information or knowledge acquisition in restoration of the Florida Everglades (Gerlak and Heikkila, 2011).

In contrast to the other rules types, the cases examined here speak less directly to aggregation, payoff, and position rules. One of the benefits of bringing the rule typology to light in the case of learning and environmental governance is that scholars may take a broader and more holistic look at institutional design in research going forward. More attention to aggregation rules, for instance may be important to consider in more formal decision-making settings where voting matters, or where such rules can lead to power indifferences that might constrain opportunities for learning across a group. Payoff rules may be important to consider where actors have clear choices in deciding between institutional change outcomes. If payoffs are high or concentrated on a particular group of actors with power or authority, such rules may make learning less relevant, as incentives for particular institutional pathways could drive outcomes. While the 
cases pointed to the value of having some actors in key leadership positions, it may also be valuable to consider how particular positions in a governance network (e.g., boundary spanners) can be structured through position rules to support learning.

At the same time, we introduced each of the rule types individually, but recognized their configural nature in any governance setting. We see how this plays out in the various cases. For example, in the community wildlife planning case, although there were tight rules mandating collaboration and establishing a learning processes, the culture of the group and a strong confidence in prior experience worked to limit experimentation (Brummel et al., 2010). In these examples, the openness of choice or scope rules constrained learning because the rules-in-use, or interpretation of the rules, did not take advantage of the opportunities to implement new ideas. On the other hand, choice rules that allow for experimentation, could be supported by both information and payoff rules that can encourage the integration of knowledge and ideas from experimental activities.

Our theorizing and analysis in this paper are subject to limitations. First, in engaging in such research, we recognize the likelihood that learning is challenging. All of the cases we studied here underscored the difficulty of deeper forms of learning that result in both fundamental changes to actors' beliefs and worldviews, alongside institutional change toward improved environmental governance. Second, we acknowledge that institutional rules are not the only factors that shape learning, and the implementation or effectiveness of rules may depend on various contextual factors. For example, it is not just the position that a person holds in the institutional setting, but also personality and leadership style that influence how people in a governance setting learn. In our earlier work examining learning in the collaborative restoration processes for the Everglades, we found a lack of direction from leaders as impediments to learning in the Everglades (Gerlak and Heikkila, 2011). Other social factors, such as trust and mutual criticism are needed for new ideas to help facilitate the acquisition and dissemination of information within a collective setting. Conversely, social dynamics that involve intolerance, suspicion, blame, or high levels of unresolved conflict can constrain the dissemination of ideas across a group, arguably because these social dynamics can discourage the willingness to share or respect others' ideas. Power dynamics also happen within groups, even when a diverse set of stakeholders are granted the authority and positions to participate (Olsson et al., 2007). The Arctic case outlined above illustrates how even when the positions are available for diverse sources of input into an organizational process, power inequalities may be felt in practice (Armitage et al., 2011).

\section{Conclusions and Future Research}

Although limited attention has been paid historically to experimentation or trial-and-error processes in studies of institutional work (Schneiberg, 2007; Hargrave and Van De Ven, 2009), research on learning can shed insights into the interplay between actors and institutional settings underlying institutional work. learning processes front and center in institutional work. In environmental governance, few would argue that learning is an important pathway toward adaptation and responsiveness to changing environmental and social conditions. It often requires intentionality or 'institutional work'. Yet, our understanding of how different institutional arrangements facilitate or impede learning remains underdeveloped. Thus, researchers need a 
more structured approach to examining the role of institutional work in learning.

Part of this work involves diagnosing how both the formal and informal rules of a governance process can shape learning. If rules are identified that severely impede opportunities for learning, more fundamental institutional work may be needed to restructure governance. The IAD's rule typology, we argue, provides a theoretically grounded platform for guiding such work. Although institutional scholars have explored how the rule typology can be used to study institutional change, or the evolution of rules and norms (Ostrom and Basurto, 2011), they have not examined how the typology helps examine learning. Similarly, while various theories of learning and environmental governance explore factors and processes that can support learning, few have taken a deep dive into the design and structure of governance rules. Therefore, to connect the rule typology to theories that examine learning, we derived some expectations about how the design of rules matters for learning. We then examined the implications of these expectations using published case studies on learning and environmental governance. Our analysis of these cases reveals that openness in boundary, scope, information, and choice rules may support learning across a variety of contexts and institutional arrangements, but we need to pay attention to the different issue contexts and types of learning when thinking about specific design features. At the same time, given that the cases offered minimal insights into position, aggregation and payoff rules, we believe scholars and practitioners should pay closer attention to these types of rules in relation to learning moving forward.

We acknowledge that our analysis was limited by the specific cases we drew upon and how, and to what extent, the authors reported their findings on learning. Further research is needed to provide adequate empirical evidence of how the individual types of rules matter, and what interaction effects they have under different contexts and conditions. Comparisons of river basin institutions through the IAD lens (see chapters in Huitema and Meijerink, 2014) offer a useful illustration of how such applications could be structured. Generally, a more systematic approach to coding rules is needed to better understand the nature of learning in social-ecological systems and how design principles support or hinder learning across a greater diversity of cases. While most of the cases examined are comparative in nature, revealing how learning occurred in some instances and not others, future research should also study the counterfactual, exploring barriers to learning, In addition, more work is needed around agency and how actors learn by deploying different strategies and how learning then affects future decisions and paths (Hargrave and Van De Ven, 2009: 102). Finally, future research can examine the environmental dynamics in the learning context to better understand what how environmental conditions interact with rules, and how rules then shape "what" is being learned across different cases. This paper offers an initial step toward laying the groundwork for such a research agenda and expanding our understanding of institutional work around learning. 


\section{References}

Argyris, C., and D. A. Scho “n. 1996. Organisational learning II. Theory, method, and practice. Reading, MA: Addison-Wesley.

Armitage, D., F. Berkes, A. Dale, E. Kocho-Schellenberg, E. Patton. 2011. "Co-management and the co-production of knowledge: Learning to adapt in Canada's Arctic." Global Environmental Change 21, 995-1004.

Armitage D., M. Marschke, R. Plummer. 2008. "Adaptive co-management and the paradox of learning." Global Environmental Change 18(1), 86-98.

Axelsson, R., P. Angelstam, L. Myhrman, S. Sädbom, M. Ivarsson, M.Elbakidze, K. Andersson, P. Cupa, C. Diry, F. Doyon, M. K. Drotz, A. Hjorth, J. Olof Hermansson, T. Kullberg, F. H. Lickers, J. McTaggart, A. Olsson, Y. Pautov, L. Svensson, and J. Törnblom. 2013. "Evaluation of Multi-level Social Learning for Sustainable Landscapes: Perspective of a Development Initiative in Bergslagen, Sweden.” Ambio 42(2), 241-253.

Bergsma, E., M. Giezen, B. Schalkwijk and C. Büscher. 2017. "Adapting to new realities: an analysis of institutional work in three cases of Dutch infrastructure planning." Journal of Environmental Planning and Management, DOI: 10.1080/09640568.2017.1391072

Beunen, Raoul and James J. Patterson. 2016. "Analysing institutional change in environmental governance: exploring the concept of 'institutional work'". Journal of Environmental Planning and Management. DOI: 10.1080/09640568.2016.1257423

Blackmore C, S. van Bommel, A. de Bruin, J. de Vries, L. Westberg, N. Powell, N. Foster, K. Collins, P. P. Roggero, G. Seddaiu. 2016. "Learning for transformation of water governance: Reflections on design from the Climate Change Adaptation and Water Governance (CADWAGO) Project." Water 8(11).

Bodin, O., and B. Crona. 2011. "Barriers and opportunities in transforming to sustainable governance: The role of key individuals." In O. Bodin \& C. Prell (Eds.), Social networks and natural resource management: Uncovering the social fabric of environmental governance (pp. 75-94). Cambridge: Cambridge University Press.

Brummel, R. F., K. C. Nelson, S. G. Souter, P. J. Jakes, and D. R. Williams, 2010. "Social learning in a policy-mandated collaboration: Community wildfire protection planning in the eastern United States.” Journal of Environmental Planning and Management, 53(6), 681-699.

Cole, D. H. 2015. "Advantages of a polycentric approach to climate change policy." Nature Climate Change 5, 114-118.

Dell'Angelo, J., P. F. McCord, D. Gower, S. Carpenter, K. K. Caylor, and T. P. Evans. "Community Water Governance on Mount Kenya: An Assessment Based on Ostrom's Design Principles of Natural Resource Management." Mountain Research and Development 36(1):102115. 
Diduck, A. 2010. "The learning dimension of adaptive capacity: Untangling the multi-level connections.” In D. Armitage \& R. Plummer (Eds.), Adaptive capacity and environmental governance (pp. 199-220). Berlin: Springer.

Dow, K., B. Haywood, N. Kettle, K. Lackstrom. 2013. "The role of ad hoc networks in supporting climate change adaptation: a case study from the Southeastern United States." Reg. Environ. Change http://dx.doi.org/10.1007/s10113-013-0440-8

Dyck, B., F. A. Starke, G. A. Mischke, and M. Mauws. 2005. "Learning to Build a Car: An Empirical Investigation of Organizational Learning." Journal of Management Studies 42(2), $387-416$.

Etheredge, L. M., and J. Short. 1983. “Thinking about Government Learning.” Journal of Management Studies 20, 41-58.

Feldman, M. S. 2000. "Organizational Routines as a Source of Continuous Change.” Organization Science 11(6), 611-29.

Folke C., J. Colding, and F. Berkes. 2002. "Synthesis: building resilience for and adaptive capacity in social-ecological systems." In F. Berkes, J. Colding, and C. Folke, editors. Navigating social-ecological systems: building resilience for complexity and change. (pp. 352383). Cambridge University Press, Cambridge, UK.

Folke, C., T. Hahn, P. Olsson, and J. Norberg. 2005. "Adaptive governance of social-ecological systems.” Annual Review of Environment and Resources, 30, 441-473.

Folke, C., S. R. Carpenter, B. Walker, M. Scheffer, T. Chapin, and J. Rockström. 2010. "Resilience thinking: integrating resilience, adaptability and transformability." Ecology and Society 15(4): 20. [online] URL: http://www.ecologyandsociety.org/vol15/iss4/art20/

Gerlak A.K., and T. Heikkila. 2011. "Building a theory of learning in collaboratives: Evidence from the Everglades Restoration Program.” Journal of Public Administration Research and Theory 21(4), 619-44.

Gunderson L., C.S. Holling, eds. 2002. Panarchy: Understanding Transformations in Human and Natural Systems. Washington, DC: Island Press.

Gunderson L., C.S. Holling, and S. Light eds. 1995. Barriers and Bridges to the Renewal of Ecosystems and Institutions. New York: Columbia Univ. Press.

Hargrave, T. J. and A. H. Van De Ven, 2009. "Institutional work as the creative embrace of contradiction." In Institutional Work: Actors and Agency in Institutional Studies of Organizations, edited by Thomas B. Lawrence, Roy Suddaby, and Bernard Leca. Cambridge University Press, 120-140.

Heikkila, T., and A.K. Gerlak. 2013. "Building a conceptual approach to collective learning: 
Lesson for public policy scholars.” Policy Studies Journal, 41(3), 484-512.

Henry, A.D. 2009. "The Challenge of Learning for Sustainability: A Prolegomenon to Theory." Human Ecology Review 16(2), 131-40.

Henry, A.D. Douglas and B. Vollan. 2014. "Networks and the Challenge of Sustainable Development." Annu. Rev. Environ. Resour. 39, 583-610.

Hoe, S. L. 2006. The Boundary Spanner's Role in Organizational Learning: Unleashing Untapped Potential. Development and Learning in Organizations 20(5), 9-11.

Huitema, D., E. Mostert, W. Egas, S. Moellenkamp, C. Pahl-Wostl, and R. Yalcin. 2009. "Adaptive water governance: assessing the institutional prescriptions of adaptive (co-)management from a governance perspective and defining a research agenda." Ecology and Society 14(1): 26. [online] URL: http://www.ecologyandsociety.org/vol14/iss1/art26/

Huntjens, P., L. Lebel, C. Pahl-Wostl, J> Camkin, R. Schulze, and N. Kranz. 2012. "Institutional design propositions for the governance of adaptation to climate change in the water sector." Global Environmental Change 22: 67-81.

Ison, R., and W. Drennan. 2007. "Illuminating the possibilities for social learning in the management of. Scotland's water." Ecology and Society, 12(1).

Jones, B. D., and F. R. Baumgartner. 2005. The Politics of Attention: How Government Prioritizes Problems. Chicago: University of Chicago Press.

Jordan,. J., D. Huitema, M. Hildén, H. van Asselt, T. J. Rayner, J. J. Schoenefeld, J. Tosun, J. Forster, and E. L. Boasson. 2015. "Emergence of polycentric climate governance and its future prospects." Nature Climate Change 5, 977-982.

Karpouzoglou, T., A. Dewulf, and J. Clark. 2016. "Advancing adaptive governance of Socialecological systems through theoretical multiplicity." Environmental Science and Policy 57, 1-9.

Keen, M., and S. Mahanty. 2006. "Learning in Sustainable Natural Resource Management: Challenges and Opportunities in the Pacific Northwest." Society and Natural Resources 19(6), 497-513.

Kraatz M. S. 2009. "Leadership as institutional work: a bridge to the other side." In Institutional Work: Actors and Agency in Institutional Studies of Organizations, edited by Thomas B. Lawrence, Roy Suddaby, and Bernard Leca. Cambridge University Press, 59-91.

Lejano, R. P., and H. Ingram. 2009. "Collaborative Networks and New Ways of Knowing." Environmental Science and Policy 12(6), 653-62.

Lipshitz, R., M. Popper, and V. J. Friedman. 2002. “A Multifacet Model of Organizational Learning." The Journal of Applied Behavioral Science 38(1), 78-98. 
Lord, C. G., and C. A. Taylor. 2009. "Biased Assimilation: Effects of Assumptions and Expectations on the Interpretation of New Evidence." Social and Personality Psychology Compass 5, 827-41.

Mezirow J. 1994. Understanding transformation theory. Adult education quarterly 44(4), 222-44.

Mezirow J. 2000. Learning as Transformation: Critical Perspectives on a Theory in Progress. New York: Jossey-Bass.

McCord, P., Dell'Angelo, J., Baldwin, E. and Evans, T. (2017), Polycentric Transformation in Kenyan Water Governance: A Dynamic Analysis of Institutional and Social-Ecological Change. Policy Stud J, 45: 633-658. doi:10.1111/psj.12168

Mezirow J. 2003. "Transformative learning as discourse.” Journal of transformative education 1(1), 58-63.

Mukhtarov, F. and A. K. Gerlak. 2014. "Epistemic forms of integrated water resources management: towards knowledge versatility." Policy Sciences 47, 101-120.

Muro, M., and P. Jeffrey. 2012. "Time to talk? How the structure of dialog processes shapes stakeholder learning in participatory water resources management." Ecology and Society, 17(1), 3. http://www. ecologyandsociety.org/vol17/iss1/art3/

Newig J., E. Kochskamper, E. Challies, N.W. Jager. 2016. "Exploring governance learning: How policymakers draw on evidence, experience and intuition in designing participatory flood risk planning." Environmental Science and Policy 55, 353-360.

Noguera-Mendez P., L. Molera, M. Semitiel-Garcia. 2016. "The role of social learning in fostering farmers' pro-environmental values and intentions." Journal of Rural Studies 46, 81-92.

Nonaka, I. 1994. “A Dynamic Theory of Organizational Knowledge Creation.' Organization Science 5(1), 14-37.

O’Brien, K. 2012. Global environmental change II: From adaptation to deliberate transformation. Progress in Human Geography 36(5), 667-676.

Olsson, P., C. Folke, and F. Berkes. 2004. "Adaptive Comanagement for Building Resilience in Social- Ecological Systems.” Environmental Management 34, 75-90.

Olsson, P., C. Folke, V. Galaz, T. Hahn, and L. Schultz. 2007. "Enhancing the fit through adaptive co-management: creating and maintaining bridging functions for matching scales in the Kristianstads Vattenrike Biosphere Reserve, Sweden.” Ecology and Society 12(1), 28. [online] URL: http://www.ecologyand society.org/vol12/iss1/art28/

Ostrom, E. 2005. Understanding Institutional Diversity. Princeton, NJ: Princeton University Press. 
Ostrom, E. 2011. "Background on the institutional analysis and development framework." Policy Studies Journal, 39(1), 7-27.

Ostrom, E., and X. Basurto. 2011. "Crafting analytical tools to study institutional change." Journal of institutional economics, 7(03), 317-343.

Pahl-Wostl, C. 2009. "A conceptual framework for analysing adaptive capacity and multi-level learning processes in resource governance regimes." Global Environmental Change, 19(3), 354365 .

Pahl-Wostl C., M. Craps, A. Dewulf, E. Mostert, D. Tabara, T. Taillieu. 2007. "Social learning and water resources management." Ecology and Society, 12(2), 5. http://www.ecologyandsociety.org/vol12/iss2/art5/

Pahl-Wostl, C., E. Mostert, D. Tabara. 2008. "The growing importance of social learning in water resources management and sustainability science." Ecology and Society 13 (1), 24.

Pahl-Wostl, C., G. Becker, C. Knieper, and J. Sendzimir. 2013. "How multilevel societal learning processes facilitate transformative change: a comparative case study analysis on flood management." Ecology and Society 18(4), 58. http://dx.doi.org/10.5751/ES-05779-180458

Pahl-Wostl C. 2016. "A multi-level perspective on learning about climate change adaptation through international cooperation.” Environmental Science and Policy.

Rogers, K. H., R. Luton, H. Biggs, R. Biggs, S. Blignaut, A. G. Choles, C. G. Palmer, and P. Tangwe. 2013. "Fostering complexity thinking in action research for change in social-ecological systems." Ecology and Society 18(2), 31. http://dx.doi.org/10.5751/ES-05330-180231

Salvini G, A. van Paassen, A. Ligtenberg, G. C. Carrero, A. K. Bregt. 2016. “A role-playing game as a tool to facilitate social learning and collective action towards Climate Smart Agriculture: Lessons learned from Apui, Brazil.” Environmental Science and Policy 63, 113 121.

Schein, E. H. 1993. "How Can Organizations Learn Faster? The Challenge of Entering the Green Room.” Sloan Management Review 34(2), 85-92.

Schmid, J.C., A. Knieram, U. Knuth. 2016. "Policy-induced innovations networks on climate change adaptation - An ex-post analysis of collaboration success and its influencing factors." Environmental Science and Policy 56, 67-79.

Schneiberg, M. 2007. "What's on the path? Path dependence, organizational diversity and the problem of institutional change in the U.S. economy, 1900-1950." Socio-economic Review 5: 4780 . 
Short, A.G., and T.P. Duane. 2016. "Learning to listen: how collaborative dialogue in regulation influences landowner adoption of best management practices on unregulatored lands." Environment and Planning C: Government and Policy 34, 320-339.

Siebenhu "ner, B. 2008. "Learning in international organizations in global environmental governance." Global Environmental Politics, 8(4), 92-116.

Siebenhu "ner, B., R. Rodela, and F. Ecker. 2016. "Social learning research in ecological economics: A survey." Environmental Science \& Policy, 55(Part 1), 116-126.

Simon, H. A. 1945. Administrative Behavior. Palo Alto, CA: Stanford University Press.

Sims, L. and A.J. Sinclair. 2008. "Learning through participatory resource management programs: case studies from Costa Rica.” Adult Education Quarterly, 58(2), 151-168.

Spinney, L. 2017. "How Facebook, fake news and friends are warping your memory." Nature 543, 168-170 (09 March 2017).

Tschakert P. and K.A. Dietrich. 2010. "Anticipatory learning for climate change adaptation and resilience." Ecology and Society 15(2): Article 11.

Tschakert P., P.J. Das, N.S. Pradhan, M. Machado, A. Lamadrid, M. Buragohain, and M.A. Hazarika.2016. "Micropolitics in collective learning spaces for adaptive decision making." Global Environmental Change, 40, 182-194.

Van Kerkhoff, L., and N. A. Szlezák. 2010. "The role of innovative global institutions linking knowledge and action." PNAS 113(17), 4603-4608.

Vinke-de Kruijf J., and C. Pahl-Wostl. 2016. "Multi-level perspective on learning about climate change adaptation through international cooperation." Environmental Science and Policy 66, 242-249.

Walters, C. J., and C. S. Holling. 1990. "Large-Scale Management Experiments and Learning by Doing." Ecology 70, 2060-8.

Weber, E. P. 2009. "Explaining Institutional Change in Tough Cases of Collaboration: 'Ideas' in the Blackfoot Watershed." Public Administration Review 69 (2), 314-27.

Zietsma, C. and B. McKnight. 2009. "Building the iron cage: institutional creation work in the context of competing proto-institutions." In Institutional Work: Actors and Agency in Institutional Studies of Organizations, edited by Thomas B. Lawrence, Roy Suddaby, and Bernard Leca. Cambridge University Press, 143-177.

Zollo, M., and S. G. Winter. 2002. "Deliberate Learning and the Evolution of Dynamic Capabilities.” Organization Science 13 (3): 339-51 
